\title{
Does Union Dissolution Lead to Unemployment? A Longitudinal Study of Health and Risk of Unemployment for Women and Men Undergoing Separation
}

\section{Ilaria Covizzi}

Research on the socio-economic consequences of divorce or union dissolution has largely focused on women's loss of income after separation. Scant attention has been paid to the effects of union dissolution on individuals' employment. Expanding the literature on the interlocked effects of divorce and health on labour market outcomes, the aim of this paper is to examine the consequences of union dissolution on employment for both women and men. The data on which this study is based are drawn from the Swiss Household Panel (SHP) study. Using Cox proportional hazards regression models, I estimate the effects of union disruption on unemployment for employed men and women in a marriage or cohabitating union over the period of 1999-2004. Findings indicate that individuals whose unions end are at a greater risk of unemployment compared to their married/cohabiting counterparts. Results also suggest the presence of relevant gender differences in the ways in which women and men experience union dissolution in relation to their labour market position. Men's hazard of unemployment is higher than that of their female counterparts, even after controlling for crucial gendered variables.

\section{Introduction}

There is a wide literature on the economic consequences of union dissolution. Most research has investigated the effects of divorce on the economic well-being of women by comparing household income before and after the separation. The focus has mostly been on women due to their disadvantaged labour market position and the propensity for divorced and separated mothers to be custodial parents. The large majority of these studies have found that women experience a greater decline in household income compared to men (Fritzell, 1990; Burkhauser et al., 1991; Smock, 1993; Jarvis and Jenkins, 1999; Smock et al., 1999; Poortman, 2000; Uunk, 2004; Andreß et al., 2006; Manting and Bouman, 2006) ${ }^{1}$. Unexpectedly, scant attention has been paid to understanding the impact of union disruption on couples' labour market outcomes. There are only a few studies in which the dissolution of the union is studied as a determinant of failure in the labour market. Kalmijn (2005) has researched the effects of divorce on men's occupational mobility and social security histories. The author has found that after marital dissolution men 
experience an increased risk of becoming downwardly mobile or experiencing social security spells. In his analysis of the relationship between marital dissolution and unemployment, Lampard (1994) has explored both casual directions. Does unemployment affect the divorce risk or does divorce affect the risk of unemployment? The relationship is found to be in both ways. Some individuals experience an increased risk of unemployment as a consequence of the dissolution of their marriages, whereas other couples experience marital breakdown after unemployment. Generally, scholars have paid more attention to the impact of unemployment on the risk of marital dissolution rather than studying the reverse causal direction (Cherlin, 1979; Jensen and Smith, 1990; Sander, 1992; Hansen, 2005). These studies have found that unemployment increases the risk of divorce although results for men and women can be different. So far, very few studies have addressed the potential disruptive effects of marital dissolution on both men's and women's labour market position, in particular, as measured in terms of increased risk of unemployment. Even fewer studies have tried to assess whether these effects are gender specific. The aim of this research is twofold. This paper addresses these shortcomings by investigating whether union dissolution may lead employed women and men to experience higher risks of unemployment compared to their married counterparts. The study also aims at examining potential gender patterns in relation to the impact of union dissolution on labour market outcomes of employed individuals.

\section{Theoretical Background}

To explain why higher risks of unemployment may be associated to union dissolution, two theoretical arguments are considered: the protective effect of marriage and the interrelation between health and employment behaviours. The theory on the protective effect of marriage is inspired by the work of Durkheim on suicide. The underlying assumption in Durkheim's work is that marriage provides married individuals with strong social ties and consequently inhibits impulses leading to suicide. The broader version of this theory assumes the centrality of marriage as a social institution, in particular, as a source of social integration. Marriage is therefore regarded as an institution providing protection not only from suicide but also from a variety of adverse life events (illness, unemployment, material, or emotional losses). Marriage has often been reported as positively associated to psychological well-being (Gove, 1973; Pearlin and Johnson, 1977; Gove et al., 1983; Amato, 2000; Simon, 2002). Numerous studies have shown that separated and divorced individuals are the least healthy when compared to the non-married group (singles and the widowed). Also, marriage appears to be more advantageous to men than women.

Sociologists have long been interested in the associations between divorce and health. Over the past 30 years research has repeatedly proven the adverse effects of separation and divorce on health by focusing on measures of psychological distress, depression, and mortality rates (Pearlin and Johnson, 1977; Gove and Shin, 1989; Simon, 2002). In attempting to account for the higher rates of distress among divorced/ separated individuals, numerous studies have referred to two dominant theoretical frameworks: the 'causation' and 'selection' hypotheses (for a review, see Amato, 2000). The assumption underlying the causation perspective is that union disruption can be a causal factor in the development of negative health outcomes. For example, the 'stress hypothesis'-a causation perspective-argues that marital dissolution is a stressful event that requires adjustment. According to this theory, marital dissolution is regarded as a process that begins when the couple still lives together and ends long after the couple ceases to live in the same household. Union dissolution can negatively affect mental health outcomes through a variety of mechanisms: loss of social integration and emotional support, increased childcare responsibilities for custodial parents, lack of contact with children for non-custodial parents, and loss of economic resources.

The second dominant framework is the selection perspective which argues that the association between the divorce event and the negative health outcomes may be a spurious one. There may be selection effects due to the selection of 'unhealthy' individuals into marriages that are more likely to end in divorce. In other words, specific characteristics of individuals preceding marital breakdown, such as previous health problems, may make them more vulnerable to stress and, consequently, to union dissolution (for a review, see Goldman, 1993). These traits have been identified as general psychological problems, propensity to depression, antisocial personality, and alcohol problems. The assumption underlying the selection argument is that some individuals are believed to have personal and/or social traits that can cause stress adjustment problems when in a couple union. As a consequence, the presence of adjustment problems increases the risk of union dissolution and finally leads 
to marital breakdown. The causation perspective (here also referred to as stress hypothesis) postulates the reverse direction of causation: it is marital dissolution itself that determines stress-adjustment problems. However, more recently, sociologists have begun to emphasize that the causation and selection mechanisms are not mutually exclusive: causation may operate alongside selection effects, and they may both play a crucial role in explaining health outcomes among separated and divorced individuals (Blekesaune and Barrett, 2005).

Nonetheless, the protective effect of marriage and the stress-adjustment theory are not the only arguments that can explain higher risks of unemployment among separated individuals. One can also argue that a rational choice approach may play a role as well. Union dissolution may lead to voluntary unemployment. Some separated men may voluntarily leave their job in order to reduce the income available to pay expensive child maintenance or spousal support. Some separated women may choose to become unemployed in order to receive greater financial support from the former partner. In fact, a number of court cases have been initiated to verify whether a parent is voluntary unemployed or underemployed for purposes of determining his or her child support obligation.

\section{Research Hypotheses}

\section{Union Dissolution Increases the Risk of Unemployment}

Based on the above discussion, the first hypothesis of this study is as follows. Union dissolution increases the risk of unemployment for both men and women, and it constitutes an even higher risk of unemployment for separated and divorced individuals when it occurs in conjunction with poor health. If being married is more advantageous than not being married, the hypothesis that union dissolution has a negative impact on individual's employment should be confirmed. It is plausible that the relationship between union dissolution and unemployment may operate through deterioration of health status due to increased psychological distress. Marital dissolution may influence individuals' health which may, in turn, negatively affect their labour market position. Research has consistently found a negative relationship between poor health and employment. Individuals in mental or physical ill health experience higher risks of leaving employment. Although the impact of ill health on both upward and downward mobility seems negligible, individuals with health problems do experience a higher risk of exiting the labour market and lower re-employment probabilities (van de Mheen et al., 1999). Research also suggests a negative effect of ill health on duration of employment (Claussen et al., 1993).

\section{The Effect of Union Dissolution on the Risk of Unemployment is Gender-Specific}

Findings on the health outcomes of married individuals indicate that men are more dependent on marriage (or cohabitation) for their well-being than women. In particular, married men have lower morbidity and mortality rates compared to their female counterparts (Lillard and Waite, 1995; Hemström, 1996). Not surprisingly, marital breakdown has been found to be more debilitating for the health of men than women's (Amato, 2000). Women seem to experience greater psychological distress well before the last stage of union dissolution (stage identified as living in two separate households), whereas the risk of ill health for men occurs later in the process of union dissolution and lasts well beyond the final stage of this process (Hemström, 1996; Gähler, 2006). Moreover, the consequences of ill health on the labour market position are more serious for men of younger cohorts compared to women of the same age group (McDonough and Amick, 2001).

The impact of gender on the risk of unemployment following marital breakdown might be reinforced not only by health factors but also by other factors such as social and family roles. Previous literature suggests that parenthood has a detrimental effect on the health of fathers who are not custodial parents, due to the limited contact they have with the children. Despite the fact that separated women suffer income decline to a much greater extent than men, they may gain more in terms of emotional support, social ties, and social integration due to the regular contact with their children. The presence of young children in the household is associated to higher survival rates, at least in the short term (Gove, 1973) and divorced individuals living with their children have healthier and more orderly lifestyle (Umberson, 1987).

Furthermore, the shift from the traditional family in which the man is the sole breadwinner to the dualearner family model and the consequent greater acceptance of women in paid jobs are likely to affect women's decisions to remain in employment even when facing difficulties caused by marital breakdown. It is well documented that for women work constitutes an important source of self-esteem and identity. 
Self-esteem appears to have stronger positive effects on women's well-being than men's (Pugliesi, 1995). However, it is worth noting that women may benefit differently from being employed depending on different work conditions, levels of occupational segregation as well as family responsibilities. Given these findings, it is plausible to expect gender differences with respect to employed individuals' responsiveness to labour market participation upon separating from their partner. If union dissolution affects transitions out of employment through an intervening process of decreased health advantage for the separated compared to those that are married, the second hypothesis of this study should also be true. The patterns of labour market participation for those experiencing union breakdown are likely to be gender specific. Women who are in paid jobs at the point of the dissolution may experience a lower risk of unemployment compared to men.

\section{Data and Analytical Approach}

The data on which this study is based are from the Swiss Household Panel (SHP) survey. The SHP is a longitudinal survey of households whose members represent the non-institutional population resident in Switzerland. It is a panel study that tracks all of the members of about 5,000 households (over 8,000 individuals), first interviewed in 1999, and every year thereafter.

The analysis spans the years 1999-2004. The sample includes observations of employed men and women aged 18-65 years, who are found in a marriage or cohabitating union, and are at risk of union dissolution and unemployment during the 5-year period. The vast majority of the studies on the consequences of couple dissolution are based on data pertaining to the dissolution of married couples. This study includes both marriages and cohabitating unions due to the increasing number of couples who decide to cohabit without being married. Consensual unions are generally reported as more unstable compared to marriages. However, continuing to omit non-marital unions from the analyses underestimates the importance of this type of living arrangement that is becoming more and more widespread and accepted. ${ }^{2}$

Separation and divorce are often associated with sample attrition, particularly among men (Fitzgerald et al., 1998). Thus, it should be noted that the sample may under-represent those with low socio-economic status and unstable marriage histories. Attrition for the SHP data seems to be modest and bias associated with sample attrition does not seem to affect regression models for unemployment. In order to test for this bias, I assigned each respondent a longitudinal weight (Latouche and Naud, 2001). Regressions based on weighted data provide estimates similar to those of regressions performed on unweighted data.

\section{Analytical Approach}

The effects of union disruption on unemployment are estimated by employing event-history analysis techniques. In particular, I use Cox proportional hazards regression models (Cox, 1972). The Cox model offers a flexible specification of time by making no assumptions about the shape of the hazard over time. The equation for the Cox proportional hazards model for the $j$ th individual is:

$$
\begin{aligned}
h\left(t \mid x_{j}\right) & =h_{\mathrm{o}}(t) \exp \left(x_{j} \beta\right) \\
& =h_{\mathrm{o}}(t) \exp \left(\beta_{1} x_{1 j}+\beta_{2} x_{2 j}+\cdots+\beta_{k} x_{k j}\right)
\end{aligned}
$$

$h\left(t \mid x_{j}\right)$ is the hazard rate (for the $j$ th individual) of transition from employment into unemployment during a specific month $(t)$, given that the $j$ th subject is employed during the prior month. $h_{\mathrm{o}}(t)$ is the baseline hazard for the $j$ th individual when the value of all the covariates equal zero. $x_{j}$ is the set of covariates integrated in the model. $\beta$ is the log-hazard ratio for the $j$ th individual. In the Cox model $h_{\mathrm{o}}(t)$ is left unspecified. The assumption is that whatever the shape of the hazard is, it is the same for every subject.

First, I examine whether the dissolution of the couple union increases the hazard rate of unemployment for both men and women by employing an additive model and testing the effect of the marriage-separation transition on the transition from employment to unemployment (model A). Second, I introduce conditional hypotheses on the effect of partnership dissolution on unemployment by testing whether the effect of union dissolution depends on the value of two conditioning variables: poor health and prior health problems. The hypothesis is that dissolution in conjunction with ill health at the time of the unemployment event increases the hazard rate (model B). Third, I examine whether marital dissolution has a differentiated effect on the hazard of unemployment for women and men and whether the effect of union dissolution changes according to the values of additional variables such as duration of union, remarriage, maintenance payment responsibilities, and receiving financial help from institutions (model C). 
Switzerland is a good case for such analysis because of the configuration of the labour market. Unemployment rates for men and women are fairly similar. Thus, the influence of a highly genderimbalanced labour market can be ruled out. In 2005 the female employment rate is one of the highest among the OECD countries (70.4 per cent) and roughly 55 per cent of such women work part-time. The unemployment rate in 2005 is relatively low at 4.5 per cent (OECD, 2006). Despite the fact that the unemployment rate for women is higher than it is for men, it is only about 1 per cent point higher ( 4.9 per cent compared to 4 per cent).

\section{Dependent Variable}

The dependent variable is the hazard rate of transition from employment into unemployment $h(t)$ during a specific month, given that one is employed during the prior month. The SHP data has the advantage of registering the exact date when the event occurred for a number of key variables, such as employment and union dissolution events. The analysis is therefore sensitive to changes in couple's employment as well as in marital histories that occur between the annual interviews. $^{3}$

\section{Sample Identification and Even-History Information}

Given that the trajectory under observation is the transition from employment to unemployment, the problem of left censoring is handled in the following way. I constructed a person-month dataset starting with the date when subjects are found in a marriage or consensual union during the observation period 19992004. These married/cohabitating subjects become at risk, and therefore enter the analysis, only at the point they are employed. If at $t=0$ (date of interview) they are inactive or unemployed, their records report values before they come at risk of loosing employment and are therefore excluded from the analysis. Thus, those who are non-employed at the beginning of the observation period enter the analysis if they become employed at any point thereafter. The failure event is the unemployment event. Due to the fact that unemployment is a repeatable event, first and all subsequent exits from the labour market are included in the analyses. When the first transition from employment to unemployment takes place, the individuals are still at risk of unemployment if they return to work at a later time. Subjects exit the analysis when they are no longer under observation, regardless of the number of failures. Employment episodes that survive to the 2004 interview or that are no longer observed are treated as censored observations. If during the observation period subjects are in a partnership, undergo a separation and afterwards remarry, they are included in the sample. This results in a sample of 4,689 persons who contribute to a total of 195,742 personmonths, 1,896 of such person-months are unemployment spells. The total number of union dissolutions measured as person-months is 22,384 -originating from about 616 separations and divorces.

\section{Explanatory Variables}

The central explanatory variables are (1) union dissolution, (2) health, and (3) gender. The exact date in which respondents reported that their union ended is used to flag the union dissolution event. The variable is treated as a dichotomous time-varying covariate, measured at the month level. It is coded ' 1 ' starting from the date of the dissolution, ' 0 ' if the subjects included in the sample are still married or remarry.

The health variable is equal to ' 1 ' if respondents state that their health status is 'so, so', 'not very well' and 'not well at all', and is equal to ' 0 ' if respondents feel 'well', or 'very well'. It is important to note that health is a yearly measurement. It is the self-reported measure of health status collected at each annual interview. A potential problem with the use of such measurement is that, depending on the date of partnership dissolution (measured at the month level), health may refer to the period prior (or subsequent) to the occurrence of the dissolution. However, this should not be a major problem because marital dissolution has been recognized as a process (rather than a discrete event) beginning while the couple still lives together and ending after the couple stops living in the same household. It is therefore plausible that declines in well-being are experienced prior to the actual partnership dissolution and last after its end. If this is true, the value of the health variable collected at the year of dissolution event is unlikely to overestimate (if subjects are already separated at the date of interview) or underestimate (if they are not yet separated at the date of interview) the potential health effect on unemployment for individuals undergoing separation.

The control variable for prior health problems indicates whether married individuals experienced health problems at the beginning of the observation period (1999-2004). It is coded ' 1 ' starting from the first year of the observation period if the respondent's health was found poor/very poor. ${ }^{4}$ 
The analysis also controls for other well-known determinants of unemployment: age, education, occupational class, presence of children, and labour market conditions (yearly unemployment rates). Age is associated with higher risks of unemployment and marital breakdown for those in younger cohorts and of younger ages. A linear and a quadratic term for age are integrated in the analysis in order to allow for possible non-linear effects of age.

Education, which is generally associated with lower risks of unemployment, better health (William and Collins, 1995), and a lower risk of marital disruption (Lyngstad, 2004), is introduced in the models as a collapsed three-category version of the original CASMIN classification (Braun and Müller, 1997). The education variable measures the highest level of education achieved by the respondents at the moment of interview. The collapsed version distinguishes three levels: (1) elementary education and lower (low: CASMIN levels 1a,1b,1c), (2) secondary education (intermediate: CASMIN levels 2a,2b,2c_gen, 2c_voc), and (3) tertiary education (high: CASMIN levels $3 a, 3 b$ ).

Current occupational class is classified according to a 5-category version of Erickson and Goldthorpe's 11-category social class scheme (Erikson and Goldthorpe, 1992). The five categories are higher grade professionals and managers, lower grade professionals and managers, routine non-manual, selfemployed, and skilled/unskilled manual. The category for self-employed farmers is combined with the selfemployed category, and the categories of unskilled, semi-skilled, and skilled workers are combined into an overall category.

The presence of children is included as both number of dependent children (up to age 16 years) living in the household and the presence of children aged 0-3 years in order to disentangle the potential age effects of children.

The yearly unemployment rate is measured as a continuous time-varying covariate ranging from 2.6 to 4.5 per cent.

Another factor that has been linked to the risk of unemployment and that is used in this study as a control variable is the experience of previous unemployment. Prior research has reported the existence of a mechanism known as 'unemployment occurrence dependence': individuals' previous unemployment experience may have negative implications for their subsequent labour market outcomes. The variable for previous unemployment is a dichotomous timevarying variable coded as ' 1 ' if respondents have experienced prior spells of unemployment since 1999, and ' 0 ' otherwise.
The nationality variable is a time-invariant binary variable indicating whether the respondent is Swiss (coded as ' 1 ') or non-Swiss (coded as ' 0 '). In Switzerland the share of foreigners in the work force is remarkably high: 22 per cent of the resident population in 2003 were foreigners. The unemployment rate for foreigners is far higher than the rate for the Swiss: 6.6 per cent compared to 2.8 per cent in 2004 , resulting in a share of 40 per cent of foreigners among the unemployed.

A part-time work indicator is integrated into the models because of the relevance of part-time employment, in particular for women, in the Swiss labour market. In 2005, 45.8 per cent of employed women were working in part-time jobs (OECD, 2006).

A variable for the union duration in years is included as a control variable in order to account for the possible differences in the labour market behaviours of individuals in a long-lasting union compared to individuals in a short union.

Lastly, two additional variables are considered: maintenance payments to persons not, or no longer, living in the household and receiving financial help from institutions. Both variables are collected at the household level and introduced as dichotomous timevarying variables. The maintenance payment variable is coded ' 1 ' if respondents have payment responsibilities to children no longer living in the household, a former partner or relative in care. The financial help variable is coded ' 1 ' if respondents receive income supplement, welfare benefits or financial help with health insurance premium from institutions.

\section{Results}

Table 1 provides descriptive statistics of the variables included in the analysis. The distribution of employment spells (averaged over the person-months) for men and women exposed to the risk of unemployment is reported.

The typical couple is married, although about 11 per cent of employed men and women in the sample live in a cohabitating union. Foreigners represent a considerable share of employed respondents: about 12 per cent. Not surprisingly, the socio-economic position of men, measured as current occupational class, is higher than that of women. About one-third of men have a high socio-economic status (higher grade professionals and managers) compared with only 10.5 per cent of women. The latter tend to be concentrated in routine-non-manual jobs (33.1 per cent compared with 5.7 per cent of men). Two other notable gender 
Table 1 Descriptive statistics of employment spells of men and women exposed to the risk of unemployment (averaged over the person-months), SHP 1999-2004

Variables

Gender

Men

Women

Union type

Marriage

Cohabitating union

Union dissolution

No

Yes

Poor Health

No

Yes

Initial health problems

No

Yes

Age (mean)

Educational attainment (CASMIN)

Low

Intermediate

High

Current occupational class (EG scheme)

Higher-grade professionals and managers

Lower-grade professionals and managers

Routine non-manual employees

Self-employed

Skilled and Unskilled manual workers

Past unemployment

No

Yes

Nationality

Swiss

Non-Swiss

Number of children living in the household 0

1

2

3

4 and over

Presence of children aged 0-3

No

Yes

Part-time work

No

Yes

Duration of union in years (mean)

Remarriage

No

Yes

Maintenance payments to persons not in $\mathrm{HH}$

No

Yes

Financial help

No

Yes

$\mathrm{N}$ (Person-months)
Total

$\%$

51.3

48.7

88.9

11.1

91.3

8.8

89.2

10.8

88.7

11.3

43.5

10.9

68.3

20.7

22.0

27.3

19.0

12.8

18.9

96.2

3.8

88.3

11.7

46.4

17.6

23.7

10.1

2.3

84.6

15.4

57.5

42.5

16.8

99.8

0.2

83.7

16.3

84.6

15.4
Men

$\% \quad$ SE

SE

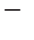

$-$

89.8

10.2

92.9

7.1

90.5

9.6

89.3

10.7

44.3

9.93

6.0

67.3

26.7

32.8

25.7

5.7

13.0

22.8

97.5

2.5

87.6

12.4

43.9

17.7

24.8

10.8

2.8

82.4

17.6

88.5

11.5

10.56

16.4

99.8

0.2

83.7

16.3

85.0

15.0

88,565
Women

$\%$ SE

$-$

87.9

12.1

89.6

10.4

87.9

12.1

88.1

11.9

42.6

16.1

69.5

14.5

10.5

29.0

33.1

12.7

14.7

94.8

5.2

89.0

11.0

49.0

17.4

22.4

9.3

1.8

86.9

13.2

24.8

75.2

17.3

10.73

99.8

0.2

83.8

16.2

84.3

15.7 
differences are observed with respect to health and previous unemployment experience. More women report poor health status and prior health problems: 12.1 per cent versus 9.6 per cent of men, and 11.9 per cent versus 10.7, respectively. The proportion of women who have recently experienced unemployment is more than double that observed among men (5.2 per cent compared with 2.5 per cent). Given the limited observation period (5 years), remarriage represents a small percentage in the sample $(0.2$ per cent). Also, it was not possible to identify those who remarried before they entered the survey. Lastly, both men and women have similar maintenance payment responsibilities (about 16 per cent) $)^{5}$ and financial help from institutions (15 per cent for men and 15.7 for women). The results of the Cox proportional hazards regression models are presented in Table 2.

\section{Model A: The Overall Effect of Union Dissolution on the Risk of Unemployment}

Model A is a baseline model in which only the additive effects of the covariates are introduced. This model controls for basic variables that are typically used in studies of the determinants of unemployment for those who have lost their job. In model A, union dissolution exerts a significant effect on the risk of unemployment. The point estimate for union dissolution in Table 2 indicates that the hazard rate of unemployment for those facing union dissolution is 76 per cent higher ${ }^{6}$ than that for those who are married. This finding supports the first hypothesis of this study. Union disruption is likely to have negative effects on the probability of remaining employed. When analysed together, married and separated men experience a lower risk of unemployment compared to their female counterpart. Their hazard rate is 11.1 per cent smaller than the corresponding hazard for women. As expected, health has a strong negative impact on unemployment. Those with poor health have a hazard rate 93 per cent greater than those in good health.

The effects of the remaining control variables are consistent with our expectations and with those found in previous studies on the determinants of unemployment. Young age, low level of education, and lower occupational classes are positively associated with higher hazard rates of transition into unemployment. For example, a 5-year increase in the age of employed individuals (starting from age 18 years) is associated with a 11.5 per cent decrease in the hazard of unemployment. In Switzerland, the highest unemployment rate by age ( 8.8 per cent) is found in the 15-24-year-old age group (OECD, 2006). No quadratic effect of age is found. Thus, the quadratic term for age is dropped. Of particular interest is the strong positive impact of past unemployment experience on the risk of future unemployment. An employed individual with previous unemployment history is estimated to face 1.5 of the hazard of an individual with no unemployment experience. This finding lends strong support to the hypothesis of 'occurrence dependence'. Finally, consistent with the demographics of the Swiss labour force, foreigners experience a significantly higher risk of unemployment. Their hazard ratio is 73 per cent greater than the hazard for the Swiss population.

\section{Model B: The Interaction Between Health and Union Dissolution and Its Effect on the Risk of Unemployment}

The additive model (model A) asserts that union dissolution has a constant effect on unemployment, while model $B$ asserts that the effect of union dissolution on the risk of unemployment depends on the value of the health status. Besides, model B controls for health selection into marriage and employment instability by introducing the effect of prior health problems and its interaction with partnership dissolution. As hypothesized, union disruption in combination with health problems has a strong negative effect on individuals' employment: the marginal hazard rate of unemployment for separated couples with poor health is about 112 per cent $[\exp (0.47+0.28)-1]$ greater than that of married individuals in good health. On the contrary, prior health problems have no statistically significant effect on the hazard rate of unemployment for separated individuals. This is in accordance with the study by Kalmijn (2005), who found that the effects of prior health problems in understanding the impact of divorce on male unemployment are limited.

This finding provides evidence for the hypothesis that it is separation, instead of early health problems, that may cause strong psychological distress and lead to a higher risk of unemployment. Yet, this result does not rule out the existence of early personality or health characteristics leading individuals to marital instability and consequently to unemployment (health selection). Instead, it implies two facts. First, prior health problems may not influence the probability of union dissolution in the direct way we would expect, but other factors such as cultural norms may intervene. Second, given that previous empirical findings on the contribution of 
Table 2 Transition from employment into unemployment: Cox proportional hazards regression models for men and women, SHP 1999-2004

\begin{tabular}{|c|c|c|c|c|c|c|}
\hline & \multicolumn{2}{|c|}{ Model A } & \multicolumn{2}{|c|}{ Model B } & \multicolumn{2}{|c|}{ Model C } \\
\hline & Coeff. & SE & Coeff. & SE & Coeff. & SE \\
\hline Men & -0.12 & 0.05 & -0.11 & 0.05 & -0.14 & 0.07 \\
\hline Union dissolution & 0.56 & 0.06 & 0.47 & 0.07 & 0.18 & 0.15 \\
\hline Age (5-year scale) & -0.12 & 0.01 & -0.12 & 0.01 & -0.07 & 0.02 \\
\hline \multicolumn{7}{|l|}{ Educational attainment (CASMIN) } \\
\hline Low (reference) & 0.00 & 0.00 & 0.00 & 0.00 & 0.00 & 0.00 \\
\hline Intermediate & -0.31 & 0.07 & -0.32 & 0.07 & -0.32 & 0.07 \\
\hline High & -0.23 & 0.09 & -0.24 & 0.09 & -0.27 & 0.09 \\
\hline \multicolumn{7}{|l|}{ Current occupational class (EG scheme) } \\
\hline Higher-grade professionals and managers (ref.) & 0.00 & 0.00 & 0.00 & 0.00 & 0.00 & 0.00 \\
\hline Lower-grade professionals and managers & 0.40 & 0.08 & 0.41 & 0.08 & 0.37 & 0.08 \\
\hline Routine non-manual employees & 0.54 & 0.09 & 0.54 & 0.09 & 0.52 & 0.09 \\
\hline Self-employed & -0.02 & 0.11 & -0.01 & 0.11 & -0.04 & 0.11 \\
\hline Skilled and Unskilled manual workers & 0.16 & 0.09 & 0.17 & 0.09 & 0.16 & 0.09 \\
\hline Past unemployment & 1.52 & 0.06 & 1.53 & 0.06 & 1.46 & 0.06 \\
\hline Yearly unemployment rate & 0.44 & 0.06 & 0.44 & 0.06 & 0.36 & 0.06 \\
\hline \multicolumn{7}{|l|}{ Nationality } \\
\hline Swiss (reference) & 0.00 & 0.00 & 0.00 & 0.00 & 0.00 & 0.00 \\
\hline Non-Swiss & 0.55 & 0.06 & 0.56 & 0.06 & 0.56 & 0.06 \\
\hline \multicolumn{7}{|l|}{ Poor health } \\
\hline No (reference) & 0.00 & 0.00 & 0.00 & 0.00 & 0.00 & 0.00 \\
\hline Yes & 0.66 & 0.06 & 0.60 & 0.07 & 0.57 & 0.07 \\
\hline Prior health problems & - & - & & & & \\
\hline No (reference) & - & - & 0.00 & 0.00 & 0.00 & 0.00 \\
\hline Yes & - & - & -0.06 & 0.08 & -0.04 & 0.08 \\
\hline Remarriage & - & - & - & - & -0.20 & 0.36 \\
\hline Maintenance payment & - & - & - & - & 0.18 & 0.07 \\
\hline Financial help from institutions & - & - & - & - & 0.26 & 0.06 \\
\hline \multicolumn{7}{|l|}{ Interactions: } \\
\hline Poor health $\times$ Dissolution & - & - & 0.28 & 0.13 & 0.31 & 0.14 \\
\hline Prior health problems $\times$ Dissolution & - & - & 0.11 & 0.15 & -0.05 & 0.16 \\
\hline Men $\times$ Dissolution & - & - & - & - & 0.37 & 0.13 \\
\hline No. of children in the household $\times$ Dissolution & - & - & - & - & -0.18 & 0.06 \\
\hline Presence of children aged $0-3 \times$ Dissolution & - & - & - & - & 0.65 & 0.17 \\
\hline Part-time work $\times$ Dissolution & - & - & - & - & 0.24 & 0.14 \\
\hline Duration of union $(4$-year scale $) \times$ Dissolution & - & - & - & - & 0.03 & 0.02 \\
\hline Maintenance payment $\times$ Dissolution & - & - & - & - & -0.46 & 0.15 \\
\hline Financial help x Dissolution & - & - & - & - & 0.09 & 0.13 \\
\hline Number of subjects & 4,571 & & 4,571 & & 4,567 & \\
\hline Number of unemployment events (person-months) & 1,896 & & 1,896 & & 1,826 & \\
\hline Number of dissolutions (person-months) & 22,384 & & & & & \\
\hline Number of subjects undergoing dissolution & 613 & & & & & \\
\hline$\chi^{2}(\mathrm{df})$ & $1,603.3$ & (13) & $1,609.9$ & (16) & $1,721.3$ & (30) \\
\hline
\end{tabular}

health selection to partnership dissolution are varied and contradictory, measures for prior health problems used to study health selection may need a rethinking. The variables used to control for health selection may not be satisfactory measures of those characteristics we believe might affect selection into divorce. Besides, it is important to note that those with health problems have been repeatedly found to have lower employment rates. As a consequence, individuals with impaired health-as they are likely to be not employed-have been selected out from the present sample of employed married individuals. Hence, the insignificant effect 
of prior health problems may also be due to an over-representation of healthy individuals in the employed group.

\section{Model C: Gender Differences in the Impact of Union Dissolution on the Risk of Unemployment}

Further variables are introduced in the Cox model to better disentangle the effects of partnership dissolution on unemployment, with a particular focus on gender patterns and familial roles. Model C (Table 2) simultaneously includes interaction terms of union dissolution with (1) health and (2) prior health problems (already present in model B), (3) gender, (4) number of children living in the household, (5) presence of children aged 0-3 years, (6) part-time work, (7) duration of union in years, (8) remarriage, (9) maintenance payment responsibilities, and (10) financial help from institutions. The introduction of additional explanatory variables and their interaction terms do not alter the conclusion about health derived from model $\mathrm{B}$.

The positive estimate for the coefficient of the interaction term between gender and union disruption shows that the effect of marital breakdown on the probability of remaining employed is more disruptive for men. Men undergoing a separation face a hazard rate 25 per cent greater than that of their female counterparts. In considering family characteristics, the risk of unemployment of separated individuals declines with the number of children below 16 years of age living in the household. In contrast, the hazard rate of unemployment increases by 43 per cent with the presence of young children. As suggested by previous research (Blekesaune and Barrett, 2005), when studying labour market outcomes in relation to union dissolution, it is important to investigate factors influencing the parental role. One of these factors is age of children. Younger children are likely to cause additional stress when adjusting to separation. Whereas children are generally proved to be a protective factor from the experience of unemployment, the presence of very young children may be an important trigger of psychological distress during the dissolution process. Moreover, despite the fact that the vast majority of custodial parents are women, the interaction between presence of young children and deterioration of marital union may also reveal fathers' difficulties with caring for children when they are custodial parents. Kiernan and Mueller (1998) have found that in Britain separated men who are custodial parents are more likely than men in partnerships, with or without children, to be economically inactive. Most of these fathers reported that caring for children was the main reason that they were out of the labour force. Blekesaune and Barrett (2005) have found that separation is more distressing for individuals with children, at least at the time of the dissolution.

To further examine gender-specific patterns, it is essential to look at the effect of part-time employment. The coefficient for the interaction between part-time employment and union dissolution indicates that those engaged in part-time work and whose partnership dissolves are more likely to loose their job compared to their full-time counterparts. Their hazard rate of unemployment is 27 per cent higher than that of those working full time. It is worth remembering that over the 5-year period the majority of employment spells experienced by women are part-time employment spells (75.2 per cent), whereas most employment spells experienced by men are full time (88.5 per cent). The estimate for the interaction between part time and union dissolution is therefore strongly indicative of the negative effect that union dissolution may have on labour market outcomes of women. This result may seem in contrast with the idea that parttimers would have higher economic needs after separation compared to full-timers. Yet, being separated part-timers does not necessarily imply not to be at high risk of unemployment. First, if the stress hypothesis is true, the effect of separation can be detrimental for the individuals' health, regardless of whether they are part-timers or full-timers. Unemployment caused by health problems is involuntary unemployment. In this sense, part-timers' economic decisions such as continuing working or even increasing the amount of work hours after separation are constrained by the health status. Second, women's part-time work is often associated with low-paid/low-status jobs. Hence, the higher hazard of unemployment for part-timers may be suggestive of the precariousness of part-time jobs. This means that if poor health of separated part-time workers affects their performance at work, part-timers are also more likely to be made redundant or dismissed compared to higher qualified full-timers. It is easier for employers to replace low-qualified employees rather than higher qualified ones. Third, it is certainly true that mothers are often the custodial parents and are therefore likely to have higher household expenditures after separation. Yet, if the separated part-timer regularly receives child maintenance allowance or spousal support, she may not have higher economic needs than a full-time worker. Also, the decision of increasing work hours for separated 


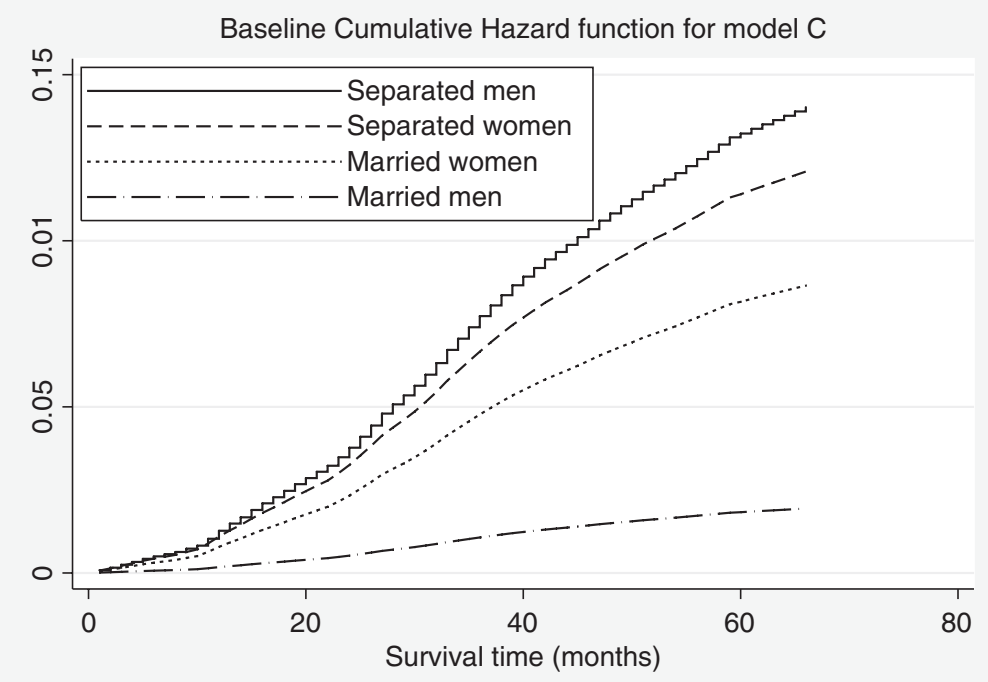

Source: SHP, 1999-2004

Figure 1 Baseline cumulative hazard function for married and separated men and women (model C)

mothers with young children implies higher costs for child care. A recent cross-national comparative study by van Damme, Kalmijn and Uunk (2006) has demonstrated that European women only slightly increase their labour supply after separation. Their results show that (1) poor health, (2) presence of young children, and (3) lack of public child care have a strong negative effect on the labour supply of separated women. In fact, a major problem facing Swiss employed women is the lack of public child-care facilities, in particular, for the early childhood years (OECD, 2004).

Model C also tests whether the effect of union disruption varies according to the duration of the union. The estimate for the product term is not statistically significant. Given that durations of marriages and cohabitations are likely to be positively correlated to age, it is plausible to think that age also captures the effect of union duration.

Remarriage has no statistically significant effect on the risk of unemployment. This may be due to the very small proportion of remarried individuals in the sample. Nonetheless, it is interesting to note that remarriage protects individuals in the sample from the risk of unemployment. Their hazard rate is 18 per cent smaller.

Against the idea that some people reduce employment after separation in order to avoid maintenance payments, the variable for payment responsibilities reveals that separated individuals with such responsibilities face a hazard rate of unemployment 25 per cent smaller compared to those who are married. On the contrary, having such responsibilities may motivate separated individuals not to loose their jobs. In other words, the role of breadwinner may continue to be a strong source of social identity even after the separation.

Lastly, financial help from institutions have a negative impact on the probability of remaining employed among married individuals but no statistically significant effect among the separated.

Figure 1 plots the baseline cumulative hazard functions based on the estimates derived from model C. The X-axis is the survival time (in months) and the $\mathrm{Y}$-axis is the cumulative hazard. The four curves represent four 'hypothetical' individuals. ${ }^{7}$

Curves for separated women and men are indicative of the relevant gender differences in the risk of unemployment of individuals undergoing a separation. The cumulative hazards of the two curves visibly rise at an increasing rate. This means that the hazard itself, which is the derivative of the cumulative hazard, is increasing. That is to say, not only men facing union breakdown experience a greater hazard of unemployment compared to women, but also their hazard increases over the 5-year period at a much faster rate than does the hazard of married men. Despite their hazard of unemployment is lower than that of separated men, this is also the case for separated women. 


\section{Conclusions and Discussion}

Research on the economic consequences of union dissolution largely focuses on income loss after separation. There is a paucity of studies examining the effects of union dissolution on individuals' employment. This study has attempted to address this research gap and shed light on the labour market consequences not only for women but also for men as well. In line with those scholars who believe that studying gender requires examination beyond the experiences of women, this paper has investigated an aspect of both women's and men's employment experiences once a partnership dissolves. The findings confirm the existence of gender-specific unemployment risks related to union dissolution and support the perspective of the protective effect of marriage, especially for men.

Individuals who experience the end of a union are found to be at a greater risk of unemployment than individuals who are married or in a cohabitating union. In particular, the results have shown that one of the mechanisms through which marital disruption affects the probability of remaining employed may be ill health. The dissolution of a union is likely to negatively influence the health of individuals by causing psychological stress-adjustment problems. The joint effect of union dissolution and poor health status significantly increases the risk of becoming unemployed. Prior health problems have no significant effect on the risk of unemployment of separated individuals. This result is consistent with a previous study on the effects of divorce on men's social security histories (Kalmijn, 2005). Therefore, union dissolution is per se an important source of distress and poor health, and consequently a possible determinant of labour market failure. However, we have seen that the health selection mechanism cannot be ruled out and is likely to operate alongside causation.

A further key finding suggests the presence of relevant gender differences in the ways in which women and men experience union dissolution in relation to their labour market position. Some men seem to 'lose' more than women when they undergo a separation process. Men's hazard of unemployment is higher than that of their female counterparts, even after controlling for crucial 'gendered' variables such as children and part-time employment. Prior research has shown that marriage is more protective for men than for women, at least in terms of social integration, social networks, and emotional support, and consequently of general well-being. Marital breakdown is therefore more detrimental to men's well-being and employment than to women's.

Important to note is that our findings do not imply that women 'gain' more than men from a union dissolution. The lower risk of losing a job for employed women undergoing a separation may be due to a self-esteem mechanism and, for those who are custodial parents, to a 'protective effect' associated to the presence of children. The most direct psychological effect of work on well-being operates through selfesteem and job satisfaction. Self-esteem from job satisfaction is found to be stronger among women than men (Pugliesi, 1995). It might be that for women undergoing union dissolution, work identity plays an important role not only for their economic sustenance but also for their social identity as well. However, it is important to keep in mind that high levels of selfesteem in relation to work are largely associated with good jobs, not all jobs.

In this sense, the results found for the interaction between union disruption and part-time employment may be a marker for the complexity of the effect of work on women's self esteem. Findings show that, compared to those working full time, those engaged in part-time jobs are more at risk of losing their job when they face union breakdown. Considering that the large majority of part-time workers are women, the adjustment pattern of employed women to union dissolution appears somehow more complex than those for men. It seems to imply a greater interconnection of determining factors such as health, occupational class, work conditions, self-esteem, role conflict, and last, but not least, familial roles.

With respect to family roles, this analysis has shown that parental responsibilities to young children (aged 0-3 years) have a detrimental effect on the labour market outcomes of parents who separate. Consistent with previous research (Mc Donough and Amick, 2001), the presence of younger children is an important factor increasing the hazard of unemployment among those undergoing marital dissolution. However, it should be noted that increasing numbers of children in the household does not seem to exert additional detrimental effects. On the contrary, greater numbers of children have a positive impact on the hazard of separated couples remaining employed. Although this result may seem incongruous, it is suggestive of the positive effects that children have on the emotional well-being of custodial parents. Custodial mothers are likely to benefit from the 'protective effect' of children-that is, the emotional closeness of the parent-child relationship and social 
networks related to their children. Whereas the 3 years following the birth of a child are certainly the most demanding in terms of child-care commitment, children in school age exert a more positive effect on the balance of work and family responsibilities for women. This finding is consistent with health studies suggesting that non-custodial parenthood is a stressful event and that non-custodial parents are more distressed than parents residing with their own minor children due to the lack of daily contact with their children (Evenson and Simon, 2005).

There is no evidence supporting the argument about voluntary employment for men with maintenance payment obligations. Separated individuals with such obligations are more likely to remain employed. Yet, a lack of suitable variables did not allow for assessing whether employed women may choose to become unemployed after separation in order to maximize the child maintenance allowance or spousal support from the former partner. A direction for future research would be to investigate whether rational choice motivations actually play a role in the 'union dissolution-unemployment' mechanism or whether they represent only a small proportion of the population of separated/divorced individuals.

From a policy perspective, it will be important in future to assess whether the negative effects of union dissolution on employment are long term or short term. Since prior unemployment experience has repeatedly been reported as a determinant for successive negative labour market outcomes, it is crucial to prevent individuals undergoing union dissolution from losing their jobs. The risk is the potential accumulation of social disadvantage and social exclusion. It would also be important to investigate whether union dissolution can have long-standing health consequences such as inactivity due to long-term sickness/ disability. To some extent transfer policies may help level the separation consequences on the labour market participation of both women and men, but initiatives should also be taken to enhance social integration, especially for men, and child-care services for women with children.

Future research is also needed to shed light on the mechanisms underlying the differential effects of union dissolution for women and men. Our analysis points to the complexity of factors involved in this process. However, the interconnectedness among the determinants of this process remains unexplored. Recent research has demonstrated the high relevance of the institutional context in shaping the economic consequences of separation and divorce (Uunk, 2004).
It would therefore be important to investigate through cross-national comparative studies how different institutional contexts affect the probability of facing unemployment for men and women undergoing separation.

\section{Notes}

1. An important exception to this finding is the study of McManus and Di Prete (2001), in which they find that in the United States the majority of men experience a decline in their income after union dissolution.

2. Avellar and Smock (2005) and Manting and Bouman (2006) are among the few studies reporting findings on the economic implications of dissolving consensual unions.

3. Respondents are asked to recall their employment status for each month between the two interviews (monthly activity calendar).

4. A measure of prior health problems relying on a retrospective question would be a better indicator of those problematic characteristics that supposedly select individuals into marital instability and union dissolution. Yet, retrospective information on early health problems is not available in the prospective panel household data used here. The use of health status at the beginning of the observation period to control for health selection is considered inadequate if the time-frame of analysis is too narrow (e.g. 2-3 years). The time window of this analysis is 5 years.

5. It is worth remembering that the maintenance payment variable is a household level variable.

6. $\Delta \hat{r}=(\exp ($ coeff $)-1) \cdot 100 \%$

7. All four individuals share the following characteristics: (1) 40 years old, (2) intermediate education level, (3) lower grade professional, (4) no children, (5) no previous unemployment experience, (6) good health status, (7) no prior health problems, (8) Swiss nationality, (9) full time, (10) not remarried, (11) no maintenance payment to persons not in the household, (12) no financial help from institutions.

\section{Acknowledgements}

This research was supported by a grant from the National Research Programme 51 on Social Integration 
and Social Exclusion by the Swiss National Science Foundation (NRP51: Project 4051-069223). The study was realised using the data collected in the 'Living in Switzerland 1999-2020' project, carried out by the SHP and supported by the Swiss National Science Foundation, the Swiss Federal Statistical Office, and the Université de Neuchâtel. I would like to thank Manfred Max Bergman, Christina Mokhtar, Anthony Cossburn and the two anonymous reviewers for their useful comments on drafts of this paper.

\section{References}

Amato, P. R. (2000). The consequences of divorce for adults and children. Journal of Marriage and the Family, 62, 1269-1287.

Andreß, H.-J., Borgloh, B., Brockel, M., Giesselmann, M. and Hummelsheim, D. (2006). The economic consequences of partnership dissolution-a comparative analysis of panel studies from Belgium, Germany, Great Britain, Italy, and Sweden. European Sociological Review, 22, 533-560.

Avellar, S. and Smock, P. J. (2005). The economic consequences of the dissolution of cohabiting Unions. Journal of Marriage and Family, 67, 315-327.

Blekesaune, M. and Barrett, A. E. (2005). Marital dissolution and work disability: a longitudinal study of administrative data. European Sociological Review, 21, 259-271.

Braun, M. and Müller, W. (1997). Measurement of education in comparative research. Comparative Social Research, 16, 163-201.

Burkhauser, R. V., Duncan, G. J., Hauser, R. and Berntsen, R. (1991). Wife or frau, women do worse: a comparison of men and women in the United States and Germany after marital dissolution. Demography, 28, 353-360.

Cherlin, A. (1979). Work Life and Marital Dissolution. In Levinger, G. and Moles, O. C. (Eds.), Divorce and Separation: Context, Causes and Consequences. New York: Basic Books, pp. 151-166.

Claussen, B., Bjorndal, A. and Hjort, P. F. (1993). Health and re-employment in a two year follow up of long term unemployed. Journal of Epidemiology and Community Health, 47, 14-18.

Cox, D. R. (1972). Regression models and life-tables. Journal of the Royal Statistical Society. Series B (Methodological), 34, 187-220.
Erikson, R. and Goldthorpe, J. H. (1992). The Constant Flux: A Study of Class Mobility in Industrial Societies. Oxford: Clarendon Press.

Evenson, R. J. and Simon, R. W. (2005). Clarifying the relationship between parenthood and depression. Journal of Health and Social Behavior, 46, 341-358.

Fitzgerald, J., Gottschalk, P. and Moffitt, R. (1998). An analysis of sample attrition in panel data: the Michigan Panel Study of Income Dynamics. The Journal of Human Resources, 33, 251-299.

Fritzell, J. (1990). The dynamics of income distribution: economic mobility in Sweden in comparison with the United States. Social Science Research, 19, $17-46$.

Gähler, M. (2006). “To Divorce Is to Die a Bit...”: a longitudinal study of marital disruption and psychological distress among Swedish women and men. The Family Journal, 14, 372-382.

Goldman, N. (1993). Marriage selection and mortality patterns: inferences and fallacies. Demography, 30, 189-208.

Gove, W. R. (1973). Sex, marital status, and mortality. The American Journal of Sociology, 79, 45-67.

Gove, W. R., Hughes, M. and Style, C. B. (1983). Does marriage have positive effects on the psychological well-being of the individual? Journal of Health and Social Behavior, 24, 122-131.

Gove, W. R. and Shin, H.-C. (1989). The psychological well-being of divorced and widowed men and women: an empirical analysis. Journal of Family Issues, 10, 122-144.

Hansen, H.-T. (2005). Unemployment and marital dissolution: a panel data study of Norway. European Sociological Review, 21, 135-148.

Hemström, O. (1996). Is marriage dissolution linked to differences in mortality risks for men and women? Journal of Marriage and the Family, 58, 366-378.

Jarvis, S. and Jenkins, S. P. (1999). Marital splits and income changes: evidence from the British Household Panel Survey. Population Studies, 53, 237-254.

Jensen, P. and Smith, N. (1990). Unemployment and marital dissolution. Journal of Population Economics, 3, 215-229.

Kalmijn, M. (2005). The effects of divorce on men's employment and social security histories. European Journal of Population, 21, 347-366.

Kiernan, K. and Mueller, G. (1998). The divorced and who divorces? CASE Paper No.7. London: Centre for Analysis of Social Exclusion-London School of Economics. 
Lampard, R. (1994). An Examination of the Relationship between Marital Dissolution and Unemployment. In Gallie, D., Marsh, C. and Vogler, C. (Eds.), Social Change and the Experience of Unemployment. Oxford: Oxford University Press, pp. 264-298.

Latouche, M. and Naud, J.-F. (2001). Weighting of the Swiss Household Panel. Wave 2-Detailed Description. Working Paper 08/01. Neuchâtel: Swiss Household Panel (SHP).

Lillard, L. A. and Waite, L. J. (1995). 'Til Death Do Us Part: marital disruption and mortality. The American Journal of Sociology, 100, 1131-1156.

Lyngstad, T. H. (2004). The impact of parents' and spouses' education on divorce rates in Norway. Demographic Research, 10, 121-142.

Manting, D. and Bouman, A. M. (2006). Short and long-term economic consequences of the dissolution of marital and consensual unions. The example of the Netherlands. European Sociological Review, 22, 413-429.

McDonough, P. and Amick, B. C. (2001). The social context of health selection: a longitudinal study of health and employment. Social Science \& Medicine, 53, 135-145.

McManus, P. A. and DiPrete, T. A. (2001). Losers and winners: the financial consequences of separation and divorce for men. American Sociological Review, 66, 246-268.

OECD(2004). Babies and Bosses-Reconciling Work and Family Life (Vol.3). New Zealand, Portugal and Switzerland. Paris: OECD.

OECD(2006). OECD Employment Outlook: Boosting Jobs and Incomes. Paris: OECD.

Pearlin, L. I. and Johnson, J. S. (1977). Marital status, life-strains and depression. American Sociological Review, 42, 704-715.

Poortman, A.-R. (2000). Sex differences in the economic consequences of separation: a panel study of the Netherlands. European Sociological Review, 16, 367-383.

Pugliesi, K. (1995). Work and well-being: gender differences in the psychological consequences of employment. Journal of Health and Social Behavior, 36, 57-71.
Sander, W. (1992). Unemployment and marital status in Great Britain. Social Biology, 39, 299-305.

Simon, R. W. (2002). Revisiting the relationships among gender, marital status, and mental health. American Journal of Sociology, 107, 1065-1096.

Smock, P. J. (1993). The economic costs of marital disruption for young women over the past two decades. Demography, 30, 353-371.

Smock, P. J., Manning, W. D. and Gupta, S. (1999). The effect of marriage and divorce on women's economic well-being. American Sociological Review, 64, 794-812.

Umberson, D. (1987). Family status and health behaviors: social control as a dimension of social integration. Journal of Health and Social Behavior, 28, 306-319.

Uunk, W. (2004). The economic consequences of divorce for women in the european union: the impact of welfare state arrangements. European Journal of Population, 20, 251-285.

van Damme, M., Kalmijn, M. and Uunk, W. (2006). The Labour Supply of Separated Women. The Impact of Individual and Institutional Factors. MPRA Paper No.1132, Munich: University Library of Munich.

van de Mheen, H., Stronks, K., Schrijvers, C. T. and Mackenbach, J. P. (1999). The influence of adult ill health on occupational class mobility and mobility out of and into employment in the the Netherlands,. Social Science \& Medicine, 49, 509-518.

Williams, D. R. and Collins, C. (1995). US socioeconomic and racial differences in health: patterns and explanations. Annual Review of Sociology, 21, 349-386.

\section{Author's Address}

Institut für Soziologie, Universität Basel, Petersgraben 27, 4051 Basel, Switzerland

Email: ilaria.covizzi@unibas.ch

Manuscript received: February 2007 